\title{
Long-term changes in zooplankton size distribution in the Peruvian Humboldt Current System: conditions favouring sardine or anchovy
}

\author{
Patricia Ayón ${ }^{1}$, Gordon Swartzmann ${ }^{2, *}$, Pepe Espinoza ${ }^{1}$, Arnaud Bertrand ${ }^{1,3}$ \\ ${ }^{1}$ Instituto del Mar del Perú (IMARPE), Gamarra y General Valle s/n Chucuito, La Punta Callao, Peru \\ ${ }^{2}$ School of Aquatic and Fisheries Science, University of Washington, Box 355020, Seattle, Washington 98195, USA \\ ${ }^{3}$ Institut de Recherche pour le Développement (IRD), UMR 212 EME, \\ Centre de Recherche Halieutique Méditerranéenne et Tropicale, Avenue Jean Monnet, BP 171, 34203 Sète Cedex, France
}

\begin{abstract}
Changes in the size distribution of zooplankton in the Humboldt Current System have been hypothesized to underlie observed changes in sardine and anchovy populations, the dominant pelagic fish species. To examine this hypothesis, the size distribution of over 15000 zooplankton data samples collected since the 1960s was qualitatively determined. Dominance of each size group of zooplankton (small, medium and large) and of euphausiids was modelled using generalized additive models as a function of year, latitude, time of day, distance from the $200 \mathrm{~m}$ isobath (a surrogate for onshelf versus off-shelf), sea surface temperature and salinity. The temporal (yr) pattern for euphausiid dominance was highly cross-correlated (i.e. was in phase) with the time series for estimated biomass of anchovy, and small zooplankton dominance with that for estimated sardine biomass. This supports the focal hypothesis based on feeding-energetic experiments, which showed energetic advantages to sardine filter feeding on smaller zooplankton and to anchovy bite feeding on larger copepods and euphausiids. Although euphausiids predominate offshore from the shelf break, anchovy biomass is generally highest on the shelf, suggesting a possible mismatch between anchovy feeding and euphausiid dominance. However, evidence concerning the offshore expansion of the anchovy range in cooler conditions, where both anchovy and euphausiids predominate, somewhat alleviates this apparent contradiction. A strong diel component to euphausiids and large zooplankton indicated diel migration for these zooplankton groups. That anchovy will preferentially eat euphausiids when they are more available (i.e. during the night and offshore) is supported by anchovy diet data.
\end{abstract}

KEY WORDS: Anchovy $\cdot$ Sardine $\cdot$ Abundance $\cdot$ Zooplankton size dominance $\cdot$ Feeding energetics Euphausiids · Humboldt Current System

\section{INTRODUCTION}

The Humboldt Current System (HCS) off the coasts of Peru and Chile is one of the 4 major upwelling systems of the world. With $<0.1 \%$ of the world ocean surface, the Peruvian landings represent $8 \%$ of the world's fish catches on average since 1970, and the landings of Peruvian anchovy Engraulis ringens alone reached $15 \%$ of the annual global fish catches in some years. The HCS has been dominated for long time peri- ods by 2 pelagic clupeid fish species (Chavez et al. 2003, Alheit \& Niquen 2004, Gutiérrez et al. 2007, Swartzman et al. 2008, Barange et al. 2009): the Peruvian anchovy and Pacific sardine Sardinops sagax. During the last $50 \mathrm{yr}$, both species showed high levels of biomass, but with apparent different periods of high and low biomass (Chavez et al. 2003). When looking farther in the past, paleostudies show that while anchovy scale deposition rates fluctuated over periods of 25 to $40 \mathrm{yr}$, only 2 peak periods of sardine occurred 
during the last $250 \mathrm{yr}$, suggesting that their biomass variations depend on other ocean-climatic factors than those which control the biomass of anchovy (Valdés et al. 2008). Also, during the $400 \mathrm{yr}$ of the Little Ice Age (1400 to 1800 s) neither anchovy nor sardine was abundant (Gutiérrez et al. 2009). During the last few decades, anchovy was particularly abundant during the 1960 s to 1973 and since the 1990s, while sardine was more abundant during the mid 1970s to 1980 s. Significantly, small pelagics, in many cases anchovy and sardine species, predominate in all of the world's major upwelling systems (Schwartzlose et al. 1999).

These species have consistent disparities in trophic dynamics, suggesting that their biomass dynamics could be, at least partly, trophically-mediated (Schwartzlose et al. 1999, van der Lingen et al. 2006, 2009, Barange et al. 2009). Changes in the size distribution of zooplankton, the major prey items of both sardines and anchovies (Espinoza \& Bertrand 2008, Espinoza et al. 2009, van der Lingen et al. 2009), have been suggested to mediate food competition between the species through differences in feeding behaviour and energetics resulting in their different sizeselection capabilities (van der Lingen et al. 2006).

This view has been developed from a variety of evidence (see van der Lingen et al. 2009 for a review). Extensive comparisons of the morphology of sardines and anchovies (many species) and of their feeding ecology suggested that differences in gill raker morphology allow sardines to efficiently filter feed on a larger size range of zooplankton (up to $1.23 \mathrm{~mm}$ and down to $10 \mu \mathrm{m}$ ) than anchovies, which do not appear to be able to effectively filter feed on zooplankton $>0.7 \mathrm{~mm}$ (van der Lingen et al. 2006). Thus, anchovies primarily feed by direct biting (particulate feeding) and show more size selective feeding, mostly taking zooplankton $>1 \mathrm{~mm}$, while sardines are apparently less size selective (van der Lingen et al. 2006, Espinoza et al. 2009).

The trophic dynamics hypothesis additionally argues that changes in upwelling patterns and currents lead to changes in zooplankton size, species structure and spatial distribution. Having higher upwelling (more nutrients) may lead to larger phytoplankton (e.g. diatoms), which have lower surface-to-volume ratios than smaller phytoplankton (e.g. dinoflagellates), which predominate in warmer, lower nutrient conditions due to higher potential uptake rates under nutrient limitation (Falkowski \& Oliver 2007, Rykaczewski \& Checkley 2008). In turn, larger zooplankton (i.e. large copepods and euphausiids, but not tunicates or gelatinous zooplankton) that may more effectively feed on large than on small phytoplankton (Peterson 1989, Walker \& Peterson 1991), thrive under higher upwelling conditions. Under warmer conditions, smaller phytoplank- ton may dominate and larger zooplankton may experience food limitation (Painting et al. 1993), resulting in dominance by smaller zooplankton (H. M. Verheye unpubl. data).

Besides deductive and laboratory evidence, several larger scale empirical studies in the HCS showed an association of anchovy with cold coastal upwelling and mixed upwelling oceanic waters (Bertrand et al. 2004, Swartzman et al. 2008). Additionally, in the California Current system (CCS), Rykaczewski \& Checkley (2008) suggested that high coastal upwelling regimes were associated with higher anchovy production while wind curl generated upwelling, which tends to be weaker, was more associated with sardine dominance. Rykaczewski \& Checkley (2008) also showed that large zooplankton in the CCS predominated in high coastal upwelling areas while smaller zooplankton were more prevalent in lower upwelling (wind curl dominated upwelling) areas.

An alternative hypothesis to inform changes in sardine and anchovy biomass, the 'optimal growth temperature' hypothesis (Takasuka et al. 2007) suggests that changes in reproductive success for anchovy and sardine under different temperature regimes may result from their having different optimal temperatures for growth in their early life stages. Also, differences in their range of habitat (sardines are generally farther offshore; Bertrand et al. 2004, 2008, Swartzman et al. 2008) may reflect differences in their ability to successfully reproduce in strong upwelling environments. These habitats are usually anoxic below a shallow oxycline (10 to $30 \mathrm{~m}$; Bertrand et al. 2008, 2010), have strong offshore surface transport of food resources, eggs and larvae, and tend to favour certain groups of phytoplankton (e.g. diatoms), which may influence both anchovy and sardine reproductive success (P. Espinoza pers. obs.). Another hypothesis to explain anchovy and sardine biomass changes, commonly accepted up to the last decade, concerned differences in efficiency of foraging on phytoplankton by primarily phytoplanktivorous anchovy and sardine, but was rejected by findings that showed both species in the HCS to be largely zooplanktivorous (Espinoza \& Bertrand 2008, Espinoza et al. 2009).

In the present study, we examined whether change in the relative size of zooplankton in the Peruvian HCS were associated with changes in sardine and anchovy biomass as suggested by the size-selective-feeding hypothesis. To this end, we used zooplankton samples collected by the Peruvian Marine Research Institute (IMARPE) between 1963 and 2005 and qualitatively estimated dominance by different size classes (small, medium and large zooplankton, and euphausiids) in these samples. 


\section{MATERIALS AND METHODS}

Data. Between 1963 and 2005, 121 surveys were carried out along the Peruvian coast, mainly to assess anchovy biomass, and more than 15000 zooplankton samples were collected opportunistically (Ayón et al. $2004,2008 b)$. Survey data covered the region up to $200 \mathrm{~km}$ from the coast (up to $500 \mathrm{~km}$ in a few surveys), though $>95 \%$ of the data were collected within $100 \mathrm{~km}$ of the coastline (Fig. 1). Sea surface temperature (SST in ${ }^{\circ} \mathrm{C}$ ) was measured using a ship-installed continuous temperature sensor at almost all zooplankton sampling locations (a thermometer was used before 1997). Sea surface salinity (SSS) was also measured using a salinometer for most of the surveys (SSS was missing for several of the earlier surveys).

Zooplankton samples were taken with Hensen nets of $0.33 \mathrm{~m}^{2}$ mouth area with a $300 \mu \mathrm{m}$ mesh, in vertical hauls between 50 and $0 \mathrm{~m}$. Samples were fixed with $2 \%$ formaldehyde buffered with borax. Zooplankton biovolume $\left(\mathrm{ml} \mathrm{m}^{-3}\right)$ was determined at the time of collection using the displacement volume method (Kramer et al. 1972). Ichthyoplankton and large coeleterates $(>2 \mathrm{~cm})$ were removed before determining the biovolume. Recently (2006 to 2008) the samples were organized and reconstituted with formalin when necessary ( $2 \%$ of the samples had dried over time).

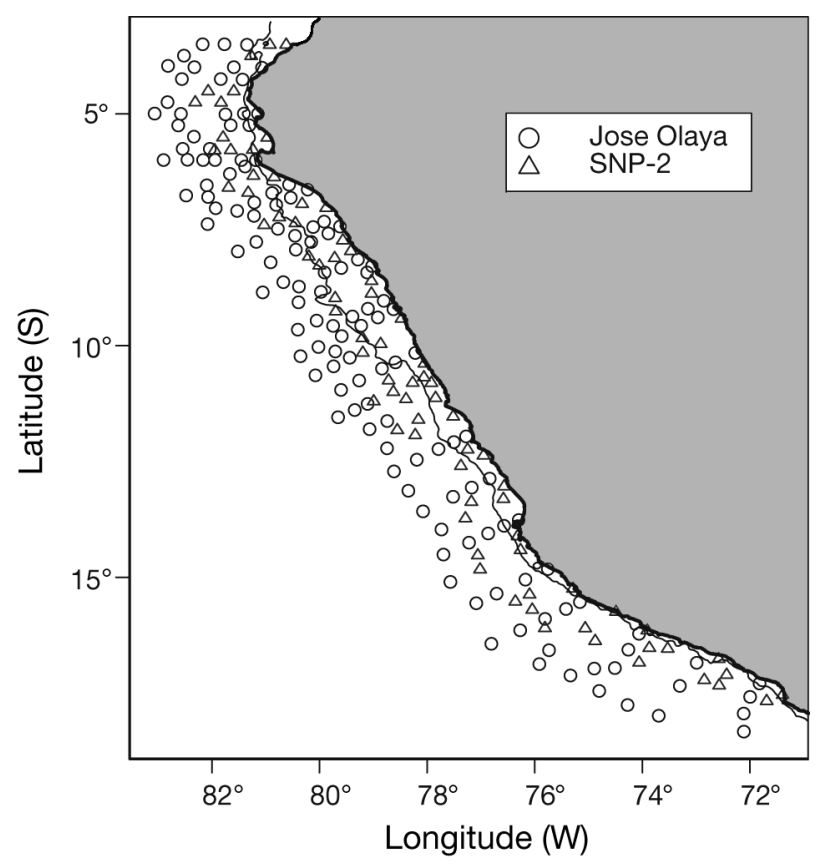

Fig. 1. Zooplankton samples off Peru for survey in July 2001 conducted aboard the IMARPE RV 'Jose Olaya' and 'SNP-2'. Coverage for this survey is representative of surveys coverage after 1983. The $200 \mathrm{~m}$ isobath is shown to identify the location of the continental platform edge. Earlier sample coverage was similar, but sample density was reduced
Zooplankton data classification. Due to the expense both in money and time for a complete assessment of the contents of the samples (e.g. species identification, size structure) a rapid, though comprehensive eyeball assessment of the size content of the zooplankton samples was undertaken by 2 observers working in tandem. For each sample, the relative dominance of 4 different size classes of zooplankton was recorded using a 0 to 3 scale, ranging from 0 for absent to 3 for dominant in the sample (more accurately, there were 3 size groups of copepod-dominated zooplankton and a 4th, generally larger sized group; euphausiids, distinguished by size and morphology). We intended dominance to represent the relative biovolume of a size group as a percentage of the total biovolume in that sample (but see Appendix 1 for biases in the method used). The 4 size classes were defined according to the current knowledge on HCS zooplankton diversity and forage fish diet (Ayón et al. 2008a, Espinoza \& Bertrand 2008, Espinoza et al. 2009). The largest size group consists of euphausiids (dominated by Euphausia mucronata). Smaller euphausiids (e.g. furcilia) were also included in the euphausiids group as they are visually distinguishable from other zooplankton and are larger than most copepods. Other zooplankton (excluding gelatinous zooplankton, which were removed from the samples) were divided into small (mostly the copepods Acartia tonsa, Clausocalanus jobei, Coryaceus dubius and Paracalanus parvus), medium (Centropages brachiatus) and large (mainly Calanus australius and Eucalanus inermis) zooplankton. These last groups are principally composed of copepods, which strongly dominate the zooplankton compartment smaller than euphausiids (Ayón et al. 2008a, Bonicelli 2008).

Validating the use of qualitative data. To test the effectiveness of qualitative data, we compared the numeric scores for dominance of the different size class and the size distribution of zooplankton biovolume for the few samples where quantitative estimates were available. We used quantitative data from 2 sources. First, we used the numbers of zooplankton in different size classes from 2 surveys (summers 1996 and 1998) for which individuals had been identified to the species level (Bonicelli 2008). Estimates of mean size of each species and life stage (Boltovskoy 1999) were used to estimate a biovolume for each species and life stage (Boltovskoy 1999) and these biovolumes were added into euphausiids, large, medium and small zooplankton groups using cut-off values of 1.3 and $2.9 \mathrm{~mm}$, respectively, to separate the species into small, medium and large zooplankton for each sample (euphausiids were explicitly identified in these samples). We then computed the correlation between the fraction of biovolume in each group and the qualitative 
estimates of dominance for the 79 available samples from the 2 surveys considered and estimated its significance using a Student's $t$-test. The second data set comprised 32 zooplankton samples from 2 surveys (summers 1965 and 1967) that had been processed using the Zooscan system (Gorsky et al. 2010) to determine the size distribution of zooplankton in the samples. Each sample was divided in 2 and filtered with 300 and $500 \mu \mathrm{m}$ filters, respectively. Each subsample was scanned using Zooscan at a resolution of $1200 \mathrm{dpi}$ following the recommended Zooscan operation protocol (Gorsky et al. 2010). Zooprocess software recorded the size of each captured image as well as providing visual snapshots for each individual counted. We extracted the Zooprocess-provided major and minor axes of an ellipse for each individual scanned in the sample. Volume was estimated by assuming an ellipsoid rotated around the major axis with 'width' provided by the minor axis. Results were converted from pixels to $\mathrm{mm}$. We computed the total biovolume in each size class using the same length limits as with the previous sample, but additionally using a limit of $5 \mathrm{~mm}$ to separate large zooplankton from euphausiids based on length. Although adult euphausiids are generally $>8 \mathrm{~mm}$, we used a smaller limit to include euphausiid furcilia, which were identified by eye as euphausiids, but are closer in size to large zooplankton. The upper limit of $5 \mathrm{~mm}$ for large zooplankton was chosen to accommodate the size of the most dominant large zooplankton (Calanus australius and Eucalanus inermis). After graphing the numbers in each sample from the different size classes, we checked the Zooscan scans by eye for samples indicating a large biovolume of euphausiid-sized organisms to eliminate cases where chaetognaths and polychaetes were dominant and identified as euphausiids based on the size criterion (where euphausiids were absent in these samples, we reduced their biovolume to zero). To compute a measure of dominance based on the Zooscan results to compare with the qualitative estimates, we took the fraction of total biovolume in each of the size groups in each sample. We then computed the correlations for each size group between concomitant qualitative and quantitative estimates.

Generalized additive model (GAM) approach. To examine the relationship between the dominance of each zooplankton size group and environmental and temporal factors, we used GAM (Hastie \& Tibshirani, 1990). GAM is a nonparametric regression technique that generalizes multivariate linear regression by relaxing the assumptions of linearity and normality, replacing regression lines by smooths. We chose a spline smoother. Choice of an underlying probability distribution was challenging because the dominance class data had a multinomial distribution (i.e. a dis- crete distribution with values $0,1,2$ or 3 ), but this cannot be used since GAM requires a distribution in the exponential family. To find the best alternative distribution, we found the best fitting Tweedie distribution using maximum likelihood estimation for model power (the tweedie.profile function in the R statistical package; Dunn \& Smyth 2008). The Tweedie set of distributions are 2 parameter distributions that include a range of distributions including the normal, Poisson, gamma and mixed gamma-Poisson models. They are commonly used to represent distributions that have a weighted probability for zero (i.e. the zero value has a non-zero probability). For our models, the best fits were provided by the Poisson distribution. An asymptotic chi-square significance test was used to test the significance of each of the covariates. We used step.gam (in the Splus statistical analysis package) for selecting the set of significant variables in the GAM that give the largest value of the Akaike Information Criterion (AIC). Step.gam chooses among options of removing any variable in the smooths or replacing it by a linear relationship. The advantage of using step.gam was that it increased the sample size for the final GAMs by adding back in samples that were removed from the full model because they had missing values for some covariates at some sample points. The covariates used for models of the dominance of small, medium and large zooplankton and of euphausiids were the latitude, year, month, time of day (time), distance from the $200 \mathrm{~m}$ isobath (dist200, in $\mathrm{km}$; positive denotes off-shelf and negative on-shelf relative to the $200 \mathrm{~m}$ isobath), SST (in ${ }^{\circ} \mathrm{C}$ ), and SSS.

Cross-correlation analysis. Biomass of sardine and anchovy was estimated using virtual population analysis (VPA; Niquen et al. 2000, R. Guevara unpubl. data), a method for estimating biomass of a species from catch data, which includes the age-distribution of the catch. VPA assumes a value for natural mortality and uses least squares estimation procedures to find annual fishing mortality rates that minimize the sum of squares difference between the actual catches and the catches estimated with different fishing mortality rates. The annual fishing mortality and effort were then used to estimate the time series of biomass (Schnute \& Richards 2002). The resultant fish biomass time series were cross-correlated with the zooplankton dominance time series (annual averages from the GAM analysis) to see whether the time patterns for each of the size classes were significantly related to the time pattern of anchovy and sardine biomass. Crosscorrelation shows how correlation between the time series changes with different lags and ascertains whether the time series are in phase, unrelated or alternate in phase. 
Change in anchovy diet. To examine the diet of anchovy relative to the spatial distribution of euphausiids, we compared the on-shelf and off-shelf carbon content of euphausiids in anchovy stomachs using an analysis of variance (ANOVA) F-test. Diet data were collected on cruises from 1996 to 2000 (Espinoza \& Bertrand 2008). ANOVA was also used on the same data to relate total stomach carbon contents on-shelf and off-shelf for both day and night to ascertain whether diel changes in feeding could reflect differences in the diel migration of zooplankton between these 2 regions.

\section{RESULTS}

\section{Validating the use of qualitative data}

Comparisons of the qualitative estimates of dominance with (1) species composition results from 2 summer surveys in 1996 and 1998 (Bonicelli 2008; Table 1) and (2) Zooscan results from 2 summer surveys in 1965 and 1967 (Table 1) support our use of qualitative estimates for dominance, especially for euphausiids (which had the strongest correlations in both cases). Correlations between the qualitative dominance estimates for all size groups used in the present study and relative biovolume estimates by size class for both sets of quantitative species composition estimates were statistically significant (Table 1). The relatively low r values in Table 1 for the 3 zooplankton size classes in the 1996 and 1998 surveys reflect not only the approximate nature of qualitative estimation, but also variability due to assumptions needed to convert species composition of the zooplankton into nominal sizes, when in fact each species has a (sometimes large) size range. The regression coefficients based on the Zooscan data, which require no nominal size assumptions, are higher than those based on the species composition data (despite the smaller sample size). Predictably, the highest $r$ values are for euphausiids, a group that is more easily distinguished from the other zooplankton by size and shape.

\section{Generalized additive model approach}

Among the covariates used for the GAM model for small zooplankton (i.e. latitude, distance from the shelfbreak, year, time of day, month, SST and SSS) only SSS, year and month were significant (Fig. 2; all significant at $\mathrm{p}<10^{-10}$ except SSS which was significant at $\mathrm{p}<10^{-8}$ ). We considered as significant only results that were significant at $\mathrm{p}<0.005$ because of the sources of uncertainty in the use of qualitative data (which could lead to spurious significant relationships with less stringent p-values). Small zooplankton dominance did not change over a wide SSS range but the GAM was more robust (narrower $95 \%$ confidence limits), for SSS between 34.6 and 35.5. In this interval, small zooplankton were more dominant in water having SSS less than 35, suggesting that they are most common in mid-salinity coastal cold water (CCW) and mixed coastal and subtropical water (MCS) and less common in equatorial (low salinity) and high salinity oceanic subtropical surface water (SSW) (see Bertrand et al. 2004 and Swartzman et al. 2008 for more details on water masses). Small zooplankton dominance increased from the early 1970s to reach a maximum during the mid-1980s and declined rapidly thereafter. Small zooplankton dominance had 2 seasonal peaks, one in winter and one in summer.

For medium-sized zooplankton dominance, SST $(\mathrm{p}<$ $\left.10^{-10}\right)$, year $\left(\mathrm{p}<10^{-10}\right)$, and month $\left(\mathrm{p}<10^{-10}\right)$ were significant covariates (Fig. 3). Medium-sized zooplankton dominance increased with SST. Over time, mediumsized zooplankton dominance increased up to the early 1990s and rapidly declined thereafter. Seasonally, they were more dominant in spring, possibly due to spring meroplankton.

Large zooplankton were most dominant greater than $150 \mathrm{~km}$ offshore of the $200 \mathrm{~m}$ isobath ( $\mathrm{p}=0.0009)$, but less in oceanic waters (SSS $>35.1, \mathrm{p}<10^{-10}$; Swartzman et al. 2008). Large zooplankton were most dominant in the 1970s $\left(\mathrm{p}<10^{-10}\right)$, declined until the late 1990s and increased thereafter (Fig. 4). They were most dominant in late spring and early summer (month effect; $\mathrm{p}=0.0005)$. Also they were more prevalent in nighttime samples $(p=0.0005)$, likely due to diel

Table 1. Coefficients of correlation (r) between qualitative dominance estimates and calculated biovolume in each size class for small, medium and large $(<1.3,1.3-2.9$ and $>2.9 \mathrm{~mm}$, respectively) copepods and euphausiids (10-25 mm) from species composition numbers in 1996 and 1998 summer surveys (df: 77) and from Zooscan processed summer surveys in 1965 and 1967 (df: 30 ). $\mathrm{p}$-values in parentheses

\begin{tabular}{|lcccc|}
\hline Data & Small & Medium & Large $^{\mathrm{a}}$ & Euphausiids $^{\mathrm{a}}$ \\
\hline Species composition & $0.22(0.027)$ & $0.33(0.0014)$ & $0.24(0.016)$ & $0.519\left(5 \times 10^{-7}\right)$ \\
Zooscan size composition & $0.433(0.013)$ & $0.526(0.0019)$ & $0.407(0.0205)$ & $0.761\left(4.3 \times 10^{-7}\right)$ \\
a Zooscan ranges for Large $=2.9-5 \mathrm{~mm}$, and euphausiids $>5$ mm, as discussed in 'Materials and methods' & \\
\hline
\end{tabular}



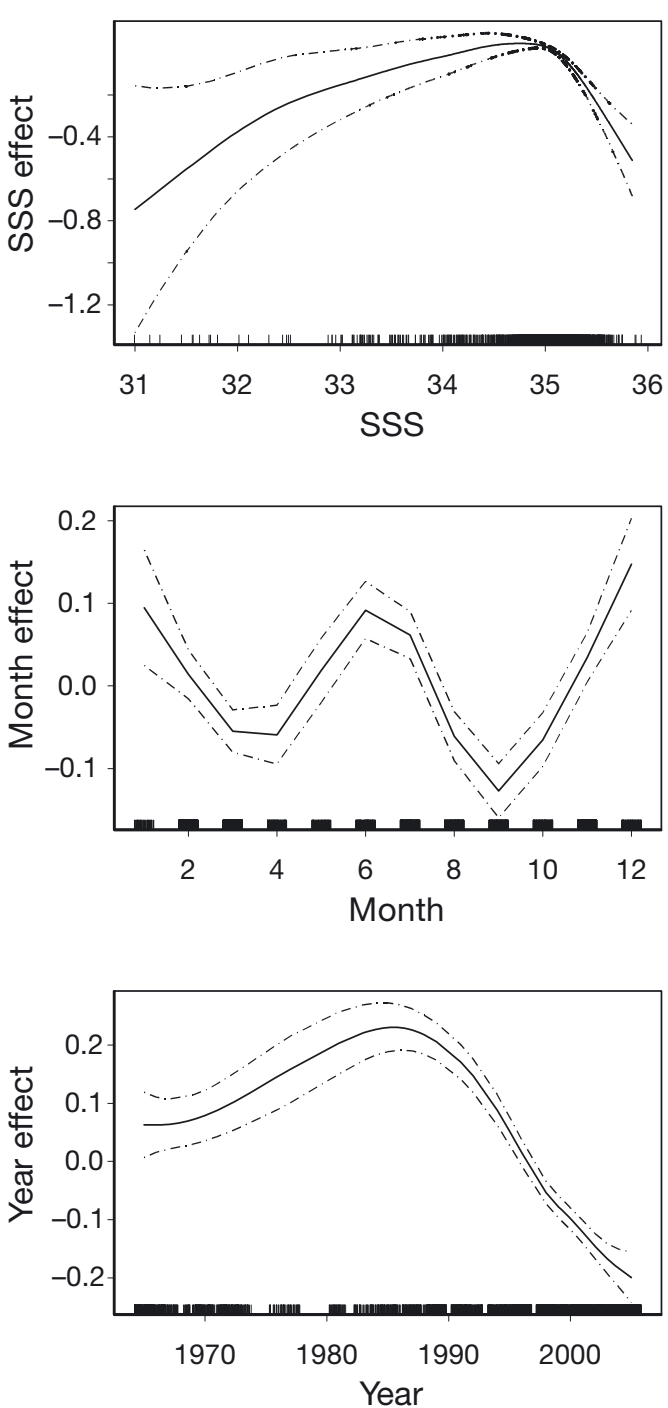

Fig. 2. Generalized additive model (GAM) results using step.gam showing smooths for the effects of significant covariates on small zooplankton dominance. Dashed lines: $95 \%$ confidence limit for best-fitting smooths. Location of data points for the covariates: tick marks along $x$-axis of the graphs. SSS: sea surface salinity

migration below the $50 \mathrm{~m}$ net range of the samples during the daytime.

Euphausiids showed a strong diel migration effect (higher at night; $\mathrm{p}<10^{-10}$ ). Their dominance was a maximum around 1970, a minimum in the early 1980s and increased thereafter (Fig. $5 ; \mathrm{p}<10^{-10}$ ). Euphausiid dominance was significantly lower on the shelf within the $200 \mathrm{~m}$ isobath $\left(\mathrm{p}<10^{-10}\right)$ than farther offshore.

\section{Cross-correlation analyses}

Using cross-correlation analysis we examined the relationship between pairs of time series (e.g. small
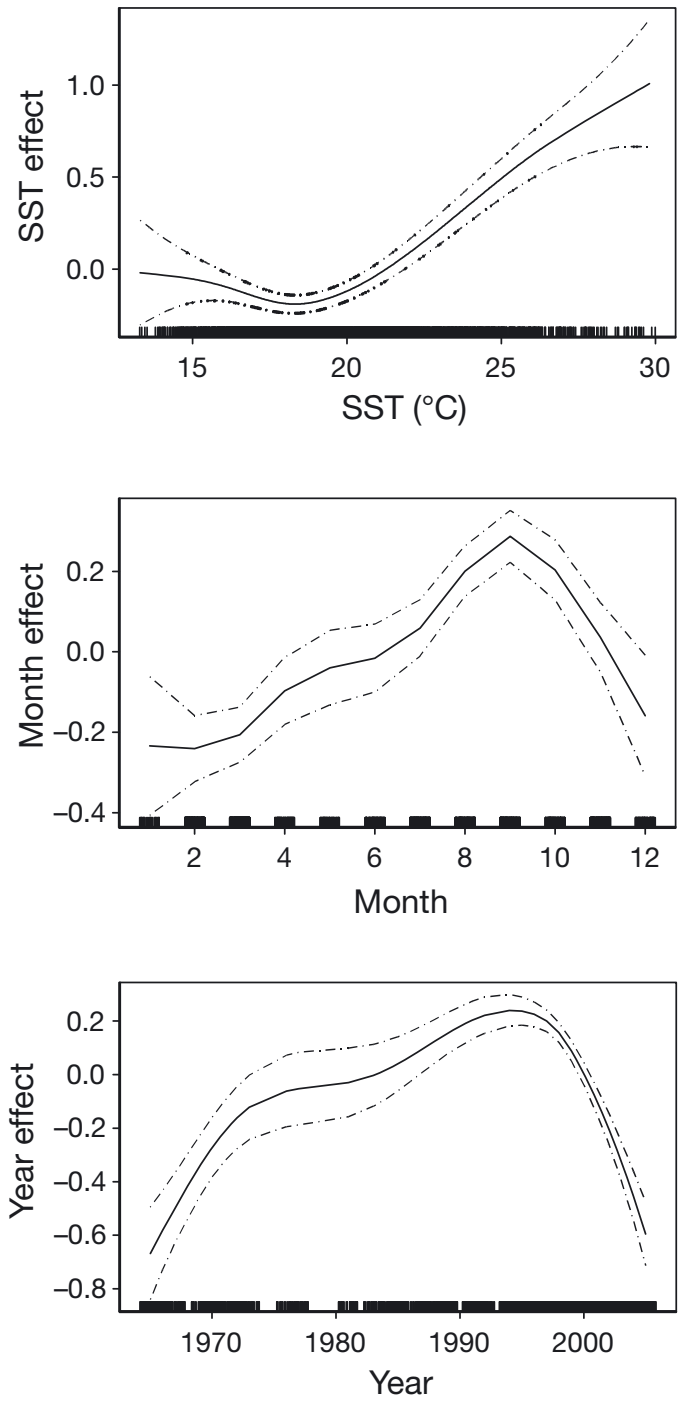

Fig. 3. GAM results using step.gam showing smooths for the effects of significant covariates on medium-sized zooplankton dominance. SST: sea surface temperature. See Fig. 2 for definitions

zooplankton dominance and sardine biomass) at different yearly time lags. In this way, synchrony or asynchrony between the time series can be considered. These results showed the small zooplankton dominance and euphausiid dominance to be synchronous with sardine biomass and anchovy biomass respectively (Fig. 6), while other combinations of fish abundance and zooplankton size class dominance time series showed varying degrees of asynchrony or lack of a temporal relationship (i.e. they were not in phase; graphs not shown). The significance levels were not corrected for possible bias due to temporal autocorrelation inherent in each of the individual time series (Fig. 6). Autocorrelation should reduce the degrees of freedom for the cross-correlation significance tests 

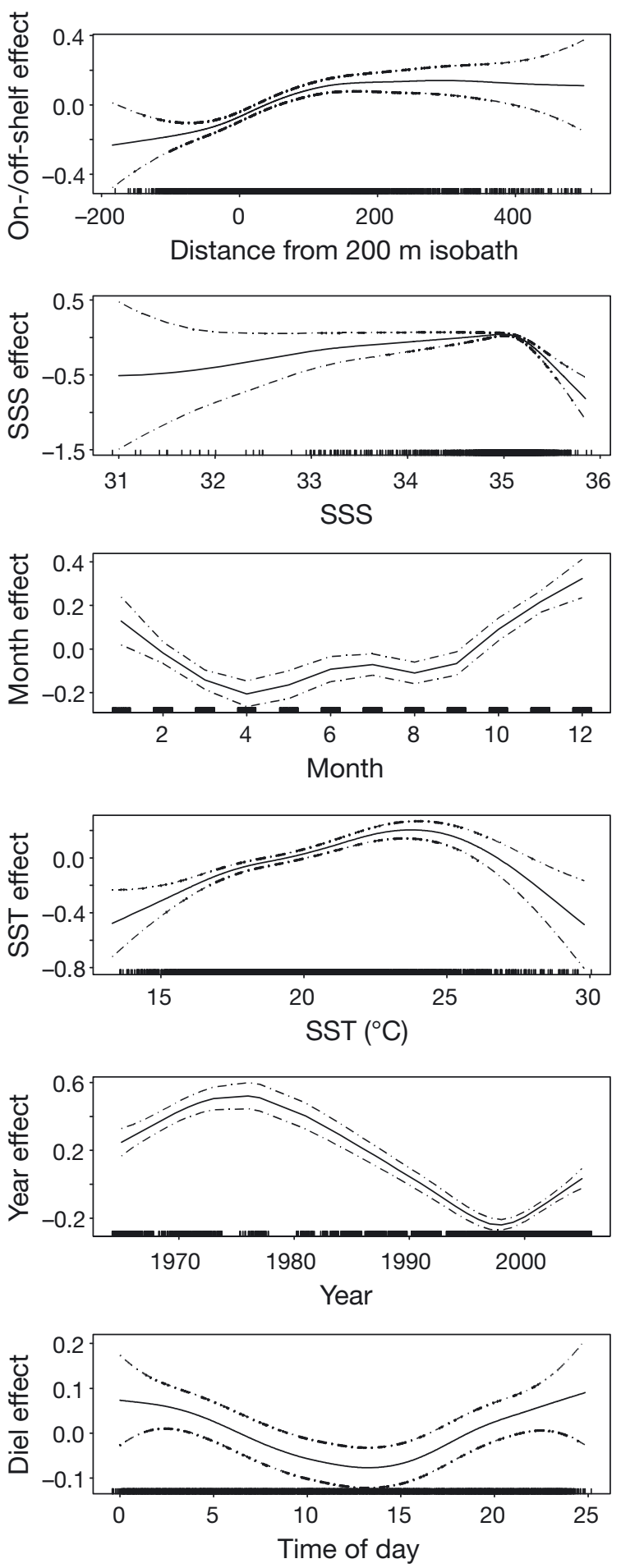

Fig. 4. GAM results using step.gam showing smooths for the effects of significant covariates on large zooplankton dominance. Sea surface salinity (SSS) and sea surface temperature (SST). See Fig. 2 for definitions

(Thomas et al. 2009). However, the high positive crosscorrelation levels for lags between -2 and $+2 \mathrm{yr}$ and that the peak in cross-correlation occurred at a lag of 0 or 1 yr suggests that the compared curves are in phase.
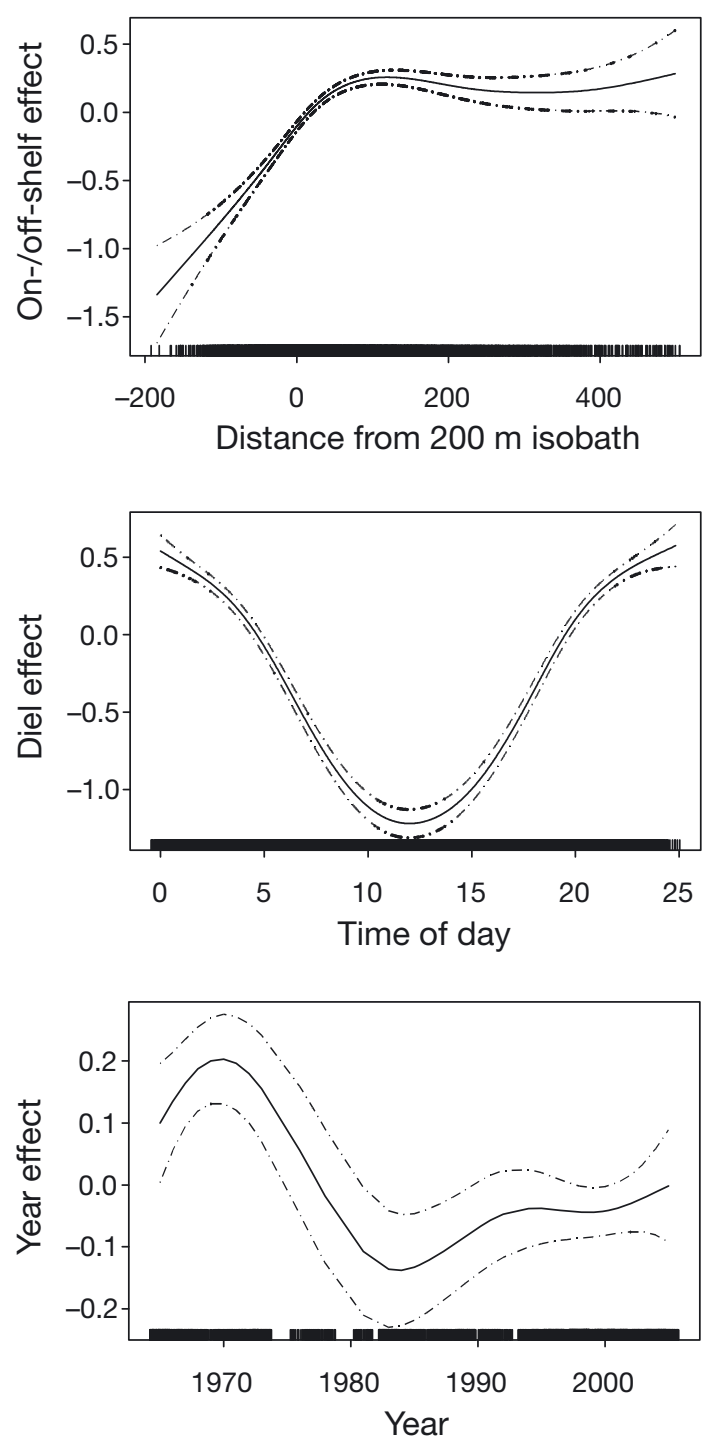

Fig. 5. GAM results using step.gam showing smooths for the effects of significant covariates on euphausiid dominance. See Fig. 2 for definitions

Also, we chose a very small $p$-value $(p=0.001)$ for significance (Fig. 7). The highest correlation between euphausiid dominance and anchovy biomass occurs at a lag of 1 yr, suggesting that changes in anchovy abundance may lag slightly behind changes in euphausiid dominance, though difference in correlation for lags between 0 and 2 yr does not change much (Fig. 7A).

\section{Euphausiids in anchovy diets}

Since euphausiids are more dominant offshore (Fig. 5), anchovy diets should consist of more euphausiids offshore than on the shelf. Also, anchovy feeding offshore should be affected by euphausiid diel migration (Fig. 5) and therefore stomach contents 

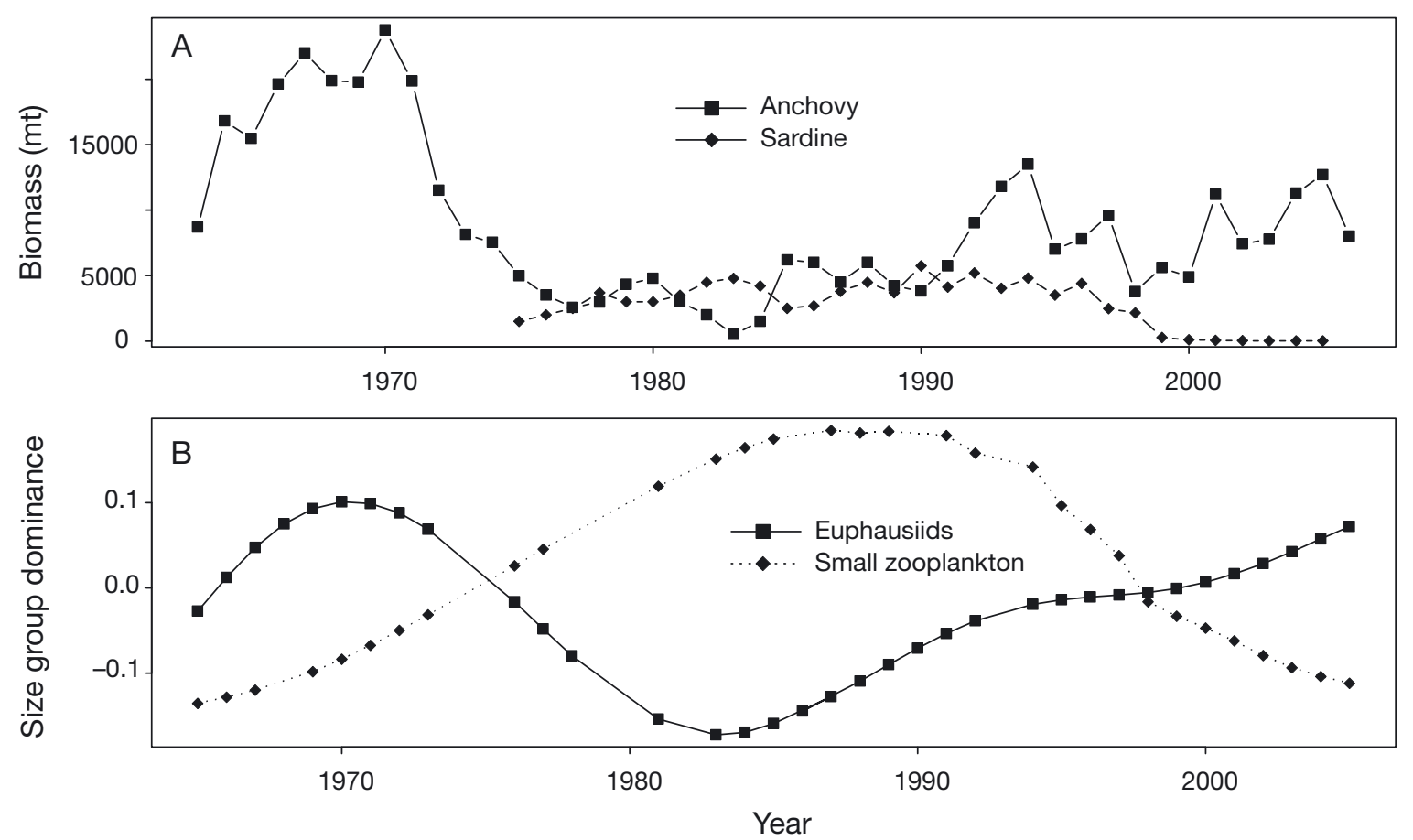

Fig. 6. (A) Anchovy and sardine biomass estimated using virtual population analysis (VPA). Source: Niquen et al. (2000), R. Guevara pers. comm. (B) Dominance of euphausiids and small zooplankton from generalized additive model (GAM) results

should be higher during the night and crepuscular periods, while over the shelf feeding and stomach contents should be more evenly distributed throughout the day. Examination of diet information (Espinoza \& Bertrand 2008, P. Espinoza unpubl. data) for the period 1996-2000 (11 surveys) demonstrate that (1) anchovy diets contained significantly more euphausiid carbon offshore than on the shelf (Table 2) and (2) that offshore anchovy diet carbon (a surrogate for feeding rate) was higher during the night and crepuscular periods, while on-shelf diet carbon was more evenly distributed throughout the day (Table 2).

\section{DISCUSSION}

\section{Validating the use of qualitative data}

Using qualitative data discriminated by eye necessitates serious consideration of their validity. Examining sample-by-sample results of the qualitative analysis in comparison to the size distribution computed by Zooscan (Table 1) revealed sources of bias and uncertainty in our qualitative dominance estimation. We discuss these in hopes that future investigators find ways to circumvent or reduce these difficulties (Appendix 1).

One aspect of the use of size-determined zooplankton groups is the possible danger of lumping ecologically dif-

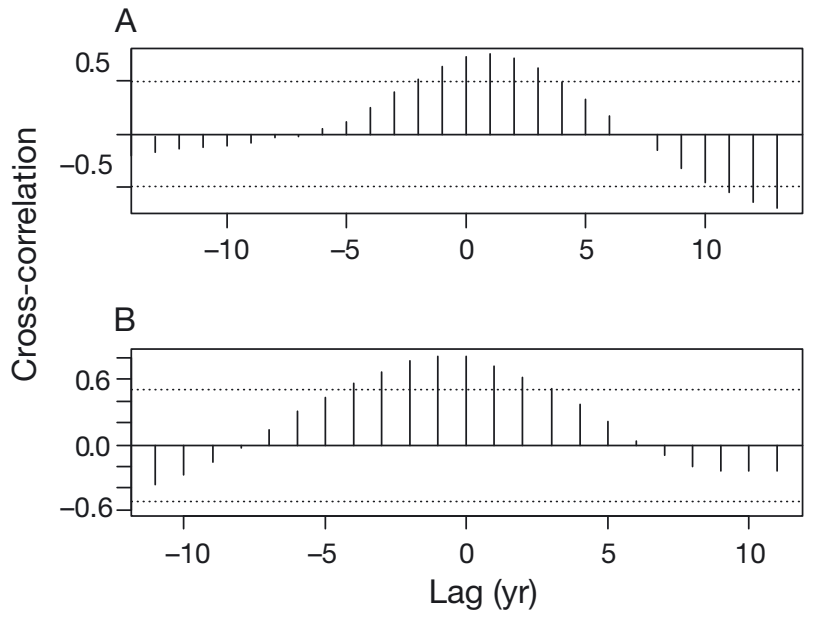

Fig. 7. Cross-correlations between (A) euphausiid dominance and anchovy biomass, and (B) small zooplankton dominance and sardine biomass at different time lags (in yr). Dotted lines: $p=0.001$ significance levels, with values above the top and below the bottom dashed lines being significant

fering species in the same size group. We cannot expect animals from the same size group to react in the same way to salinity, month, or even year. However, due to the general dominance of the large, medium and small zooplankton groups by copepods (Ayón et al. 2008a), we expect that the patterns observed in the GAM analysis hold for a majority of the biota in each group. 
Table 2. Comparison of euphausiids carbon biomass ( $\mu \mathrm{g} C$ ) in anchovy stomachs on- and off-shelf, and diel differences between total anchovy diet carbon ( $\mu \mathrm{g}$ C) on- and off-shelf. Significance tests are based on ANOVA F-tests. Median and range (95\% CI) for each option. ns: not significant

\begin{tabular}{|c|c|c|c|c|c|c|}
\hline & \multicolumn{2}{|c|}{ Euphausiid biomass ( $\mu \mathrm{g} C$ ) } & \multirow[b]{2}{*}{ Night on-shelf } & \multicolumn{2}{|c|}{ Diet carbon $(\mu \mathrm{g} C)$} & \multirow[b]{2}{*}{ Day off-shelf } \\
\hline & On-shelf & Off-shore & & Day on-shelf & Night off-shelf & \\
\hline Median & 0 & 943 & 1409 & 901 & 3926 & 2026 \\
\hline $95 \%$ CI & $0-1308$ & $0-5307$ & $244-4503$ & $162-3148$ & $1328-12862$ & $653-4580$ \\
\hline ANOVA $F$ & \multicolumn{2}{|c|}{61.4} & \multicolumn{2}{|c|}{1.17} & \multicolumn{2}{|r|}{14.9} \\
\hline ANOVA $\mathrm{p}$ & \multicolumn{2}{|c|}{$1.23 \times 10^{-14}$} & \multicolumn{2}{|c|}{0.279 (ns) } & \multicolumn{2}{|c|}{0.00013} \\
\hline
\end{tabular}

Despite the sources of bias and uncertainty in the scheme, we maintain that the large number of samples treated permit identifying large-scale temporal and spatial patterns in dominance that are strong enough to appear through the 'haze' of uncertainty, the 'slant' of bias due to human perception (Appendix 1), the lumping of multiple zooplankton species into speciesindiscriminate size groups, and leaving unsampled a potentially important component of the small zooplankton eaten by sardine and anchovy (due to the $300 \mu \mathrm{m}$ mesh net).

\section{Zooplankton size dominance and the selective feeding hypothesis}

The results from this work support the hypothesis that differences in feeding energetics between sardine and anchovy, along with changes in the size composition of zooplankton and the dominance of euphausiids, are strongly linked to periods of higher biomass for anchovy or sardine (Schwartzlose et al. 1999, van der Lingen et al. 2006, 2009). However as discussed in the next 2 sections, differences in feeding dynamics alone may not explain all aspects of the population dynamics of anchovy and sardine.

\section{Anchovy and euphausiids}

Anchovy biomass was synchronous with the dominance of euphausiids and the correlation between euphausiid dominance and anchovy biomass was higher than the correlation of anchovy biomass with overall zooplankton biovolume (cross-correlation at lag 0: $r>0.7$ in Fig. 7 versus $r<0.3$ for the anchovyzooplankton biovolume correlation given in Ayón et al. $2008 b)$. These results support the importance of euphausiids in anchovy diet, feeding success and, more generally, population dynamics (Espinoza \& Bertrand 2008, Espinoza et al. 2009).

The synchrony between euphausiid dominance and anchovy biomass begs the question of an apparent dis- crepancy between the onshore-offshore distribution of anchovy and that of euphausiids. The centroids of anchovy biomass are within $60 \mathrm{~km}$ of the coast and anchovy biomass appears to decline with distance from the coast (Gutiérrez et al. 2007, Swartzman et al. 2008, Simmonds et al. 2009) while euphausiid dominance is lower on the shelf than farther offshore (Fig. 5). Anchovy are primarily associated with upwelled CCW and MCS (Bertrand et al. 2004, Swartzman et al. 2008), which affect their range, since the coverage of the HCS by these waters is greater and extends farther offshore during high upwelling years. This would increase the overlap between the range of anchovy and the region of euphausiid dominance during cooler periods. There may be additional reasons why the anchovy predominates close to the shelf. For example, there may be reproductive advantages for anchovy, whose breeding can extend over most of the year (M. Niquen unpubl. data), to remain over the shelf, such as increased retention of larvae on-shelf (Lett et al. 2007, Brochier et al. 2008). Additionally, the higher primary production in CCW may provide essential nutrients required for anchovy reproduction (e.g. in diatoms, which are more common in CCW than other waters; P. Espinoza unpubl. data). Nonetheless, if anchovy dominate over the shelf but not euphausiids, we would expect (1) an explanation for why euphausiids are less abundant on the shelf and (2) a difference in diet between anchovy captured on the inner shelf and those captured beyond the $200 \mathrm{~m}$ isobath with fewer euphausiids in the stomachs of on-shelf anchovy. As shown earlier, comparison of euphausiid carbon in anchovy stomachs on- and offshelf show euphausiids to be more prevalent in offshelf diets (Table 2).

There are 3 possible (non-mutually exclusive) explanations for euphausiids predominating beyond the $200 \mathrm{~m}$ isobath: (1) There is reduced predation offshelf, in particular because euphausiids can perform large vertical diel migration and take refuge in the oxygen minimum zone during the day (Escribano et al. 2009). That off-shelf anchovy diets are affected by euphausiid diel migration, while on-shelf diets are less so, is supported by our results showing anchovy 
stomachs to be fuller offshore during the night (when euphausiids are more available), while on-shelf there is no significant change in stomach fullness between day and night (Table 2). (2) The euphausiid abundance near shore may be reduced (local depletion, as noted in Ayón et al. 2008b) by the high biomass of anchovy near shore or natural selection may favour euphausiids farther offshore because they are less exposed to anchovy predators. (3) Euphausiids appear to be able to maintain their position beyond the shelf break due to diel migration, which allows them to move in opposite directions above and below the shear zones that develop between opposite flowing cross-shelf and along-shelf currents (i.e. these currents flow in opposite directions above and below the shear zones) on the offshore side of the shelf break (as found, for example, by Lu et al. 2003 off the coast of Vancouver Island and by Swartzman et al. 2005 in the CCS off the western USA). Moving in a circular fashion thereby allows euphausiids to maintain their position without having to swim against currents. However, being too far offshore would not be good for euphausiids because in these offshore waters there is little effect of upwelling, and feeding conditions would likely be reduced, although they would be less susceptible to predation by anchovy.

\section{Sardine and small zooplankton}

Sardine biomass was synchronous with the dominance of small zooplankton, which in turn corresponds to periods of generally warmer, lower upwelling conditions. These results support the hypothesis that sardine's capacity to efficiently filter-feed zooplankton over a large size range gives them a competitive advantage where small zooplankton is dominant (van der Lingen et al. 2006). Also, our results are consonant with observations that sardines feed on smaller zooplankton than do anchovies in upwelling systems (van der Lingen et al. 2009) and in the HCS in particular (Espinoza et al. 2009). Therefore, our results support the hypothesis that periods of low dominance of large zooplankton disfavours anchovy and gives an energetic advantage to predominately filter feeding sardines.

Although sardine may have an advantage when small zooplankton dominate, Espinoza et al. (2009) showed that, at least from 1996 to 1998, sardine diets in the HCS contained surprisingly large amounts of euphausiids (albeit much less than anchovy diets), comprising, on average, more than $1 / 3$ of sardine prey carbon content. Therefore, even if filter-feeding by sardines is energetically more efficient than particulatefeeding (for some swim speeds; van der Lingen 1995), sardines in the HCS appear to forage on large as well as small zooplankton. Why then do sardines not do better during cooler periods dominated by euphausiids? Available data on sardine feeding in the HCS are insufficient to address a pure energetic-based explanation for this. Perhaps lower sardine populations during cooler periods could be due, in part, to other environmental factors (see for instance the habitat-based hypothesis in Bertrand et al. 2004, 2008 and Swartzman et al. 2008).

That observed diets of sardine contained more euphausiids than expected, and that the apparent distribution of anchovy was onshore of that of their preferred euphausiid prey suggests further study of the fish diets relative to the distribution of different size classes of prey. One fruitful approach to these questions might be relating anchovy and sardine diets to the local distribution of prey size within an 'influence area' of the collected stomach data, as was done to examine local depletion of zooplankton by looking at proximate biomass of anchovy and sardine to the zooplankton biovolume samples (Ayón et al. 2008b).

As more quantitative zooplankton size distribution data become available, the qualitative dominance from this paper can be replaced by the fraction of total carbon or biovolume in the samples in different size groups. The same analyses can then be conducted with greater confidence without the sources of variability inherent in eyeball estimations of sizes of zooplankton in jars and their relative dominance. We can expect improvements in these data to better inform the types of analyses conducted here. Yet, despite the sources of bias and error in the data (Appendix 1), we are confident, given the small p-values for the year effect on euphausiid and small zooplankton dominance (Figs. 2 \& 5) and the apparent synchrony of these time series with anchovy and sardine biomass respectively (Fig. 7, Table 2), that qualitative data are sufficient to support the size-selective feeding hypothesis to explain differences over time in biomass between sardine and anchovy in the HCS.

Acknowledgements. This work would not have been possible without the availability of zooplankton samples and supporting environmental data collected dutifully using the same protocol over a long time period and archived by IMARPE. This work was supported in part by the US National Science Foundation through grant no. NSF0526392 to G.S. and by UR097, UMR212 and the LMI DISCOH from IRD to A.B. We appreciate the help of L. Vasquez of IMARPE to complete the time series by inclusion of time of day, temperature and salinity for many of the earlier surveys. The zooplankton samples were organized and reconstructed by D. Chang and the samples were qualitatively assessed for size class by N. Serrano and especially J. Correa. They were trained by O. Lozano of IMARPE. 


\section{LITERATURE CITED}

Alheit J, Niquen M (2004) Regime shifts in the Humboldt Current ecosystem. Prog Oceanogr 60:201-222

Ayón P, Purca S, Guevara-Carrasco R (2004) Zooplankton volume trends off Peru between 1964 and 2001. ICES J Mar Sci Symp 61:478-484

Ayón P, Criales-Hernandez MI, Schwamborn R, Hirche HJ (2008a) Zooplankton research off Peru: a review. Prog Oceanogr 79:238-255

Ayón P, Swartzman G, Bertrand A, Gutiérrez M, Bertrand S (2008b) Zooplankton and forage fish species off Peru: large-scale bottom-up forcing and local-scale depletion. Prog Oceanogr 79:208-214

Barange A, Coetzee J, Takatsuka A, Hill K and others (2009) Habitat expansion and contraction in anchovy and sardine populations. Prog Oceanogr 83:251-260

Bertrand A, Segura M, Gutiérrez M, Vásquez L (2004) From small-scale habitat loopholes to decadal cycles: a habitatbased hypothesis explaining fluctuation in pelagic fish populations off Peru. Fish Fish 5:296-316

Bertrand A, Gerlotto F, Bertrand S, Gutiérrez M and others (2008) Schooling behaviour and environmental forcing in relation to anchoveta distribution: an analysis across multiple spatial scales. Prog Oceanogr 79:264-277

Bertrand A, Ballón M, Chaigneau A (2010) Acoustic observation of living organisms reveals the oxygen minimum zone. PLoS ONE 5(4):e10330

Boltovskoy D (ed) (1999) South Atlantic zooplankton. Blackhuys Publishers, Leiden

Bonicelli J (2008) Distribucion especial, composicion especifica y abundancia del zooplankton en la Costa Peruana durante los años 1996 y 1998. MSc thesis, Universidad Nacional Agraria La Molina, Lima

Brochier T, Azeddine Ramzi A, Lett C, Eric Machu E, Amina Berraho A, Pierre Fréon P, Santiago Hernández-León S (2008) Modelling sardine and anchovy ichthyoplankton transport in the Canary Current System. J Plankton Res 30:1133-1146

Chavez FP, Ryan J, Lluch-Cota SE, Niquen M (2003) From anchovies to sardines and back: multidecadal change in the Pacific Ocean. Science 299:217-221

Dunn PK, Smyth GK (2008) Evaluation of Tweedie exponential dispersion model densities by Fourier inversion. Stat Comput 18:73-86

Escribano R, Hidalgo P, Krautz C (2009) Zooplankton associated with the oxygen minimum zone system in the northern upwelling region of Chile during March 2000. DeepSea Res II 56:1083-1094

Espinoza P, Bertrand A (2008) Revisiting Peruvian anchovy (Engraulis ringens) trophodynamics provides a new vision of the Humboldt Current system. Prog Oceanogr 79: 215-227

Espinoza P, Bertrand A, van der Lingen CD, Garrido S, Rojas de Mendiola B (2009) Diet of sardine (Sardinops sagax) in the northern Humboldt and comparison with the diets of clupeoids in this and other eastern boundary upwelling systems. Prog Oceanogr 83:242-250

Falkowski PG, Oliver MJ (2007) Mix and match: how climate selects phytoplankton. Nat Rev Microbiol 5:813-819

Gorsky G, Ohman MD, Picheral M, Gasparini S and others (2010) Digital zooplankton image analysis using the Zooscan integrated system. J Plankton Res 32:285-303

> Gutiérrez M, Swartzman G, Bertrand A, Bertrand S (2007) Anchovy and sardine spatial dynamics and aggregation patterns in the Humboldt Current ecosystem, Peru, from 1983-2003. Fish Oceanogr 16:155-168
Gutiérrez D, Sifeddine A, Field DB, Ortlieb L and others (2009) Rapid reorganization in ocean biogeochemistry off Peru towards the end of the Little Ice Age. Biogeosciences 6:835-848

Hastie T, Tibshirani R (1990) Generalized additive models. Chapman \& Hall, London

Kramer D, Kalin MJ, Stevens EG, Thrailkill JR, Zweifel JR (1972) Collecting and processing data on fish eggs and larvae in the California Current region. NOAA Tech Rep NMFS Circ 370:1-38

> Lett C, Penven P, Ayón P, Fréon P (2007) Quantification of enrichment, concentration and retention processes in relation to anchovy (Engraulis ringens) ichthyoplankton distribution in the northern Humboldt upwelling ecosystem. J Mar Syst 64:189-200

> Lu B, Mackas DL, Moore DF (2003) Cross-shore separation of adult and juvenile euphausiids in a shelf-break alongshore current. Prog Oceanogr 57:381-404

Ñiquen MC, Espino MS, Bouchón M (2000) Analisis de la poblacion de anchoveta Peruana durante el periodo 1961-1999. Bol Inst Mar Peru 19:103-107

Painting SJ, Moloney CL, Lucas MI (1993) Simulation and field measurements of phytoplankton-bacteriazooplankton interactions in the southern Benguela upwelling region. Mar Ecol Prog Ser 100:55-69

Peterson WT (1989) Zooplankton feeding and egg production in comparison to primary production along the west coast of South Africa. Proc Plankton Dyn Mini-Symp, May 1989, Cape Town, South Africa. Benguela Ecology Programme Rep 17:1-5

Rykaczewski R, Checkley DM Jr (2008) Influence of ocean winds on the pelagic ecosystem in upwelling regions. Proc Natl Acad Sci USA 105:1965-1970

Schnute JT, Richards LJ (2002) Surplus production models. In: Hart PJB, Reynolds JD (eds) Handbook of fish biology and fisheries, Vol 2. Blackwell Science, Oxford, p 105-126

Schwartzlose RA, Alheit J, Bakun A and others (1999) Worldwide large-scale fluctuations of sardine and anchovy populations. S Afr J Mar Sci 21:289-347

Simmonds J, Gutiérrez M, Chipollini A, Gerlotto F, Woillez M, Bertrand A (2009) Optimizing the design of acoustic surveys of Peruvian anchoveta. ICES J Mar Sci 66: 1341-1348

Swartzman G, Hickey B, Kosro M, Wilson C (2005) Poleward and equatorward currents in the Pacific Eastern Boundary Current in summer 1995 and 1998 and their relationship to the distribution of euphausiids. Deep-Sea Res II 52:73-88

> Swartzman G, Bertrand A, Gutiérrez M, Bertrand S, Vasquez L (2008) The relationship of anchovy and sardine to water masses in the Peruvian Humboldt Current System from 1983-2005. Prog Oceanogr 79:228-237

> Takasuka A, Oozeki Y, Oaki I (2007) Optimal growth temperature hypothesis: Why do anchovy flourish and sardine collapse or vice versa under the same ocean regime? Can J Fish Aquat Sci 64:768-776

Thomas AC, Brickley P, Weatherbee R (2009) Interannual variability in chlorophyll concentrations in the Humboldt and California Current Systems. Prog Oceanogr 83:386-392

Valdés J, Ortlieb L, Gutiérrez D, Marinovic L, Vargas G, Sifeddine A (2008) 250 years of sardine and anchovy scale deposition record in Mejillones Bay, Northern Chile. Prog Oceanogr 79:198-207

> van der Lingen CD (1995) Respiration rate of adult pilchard Sardinops sagax in relation to temperature, voluntary swimming speed and feeding behaviour. Mar Ecol Prog Ser 129:41-54

van der Lingen CD, Hutchings L, Field JG (2006) Compara- 
tive trophodynamics of anchovy Engraulis encrasicolus and sardine Sardinops sagax in the southern Benguela: Are species alternations between small pelagic fish trophodynamically mediated? Afr J Mar Sci 28:465-477 van der Lingen $C D$, Bertrand A, Bode A, Brodeur R and others (2009) Trophic dynamics of small pelagic fish. In: Checkley DM Jr, Roy C, Alheit J, Oozeki Y (eds) Climate change and small pelagic fish. Cambridge University Press, Cambridge

Walker DR, Peterson WT (1991) Relationships between hydrography, phytoplankton production, biomass, cell size and species composition, and copepod production in the southern Benguela upwelling system in April 1988. S Afr J Mar Sci 11:289-305

Appendix 1. Sources of bias and uncertainty in qualitative zooplankton dominance data

\section{Relative-absolute size paradox}

The size limits used for distinguishing small, medium and large zooplankton depend on the size distribution in the existing sample, which changes from sample to sample (i.e. the size class ranges determined by eye are not consistent from sample to sample).

\section{Effect of overall biovolume on the perception of domi- nance}

In small biovolume samples, the tendency was to downgrade the dominance of a group. Thus, for example, when biovolume was low and the entire sample consisted of small zooplankton, the dominance factor was sometimes listed as 1 (rather than 3, which would be appropriate). Alternatively, with large samples there was a tendency to increase dominance because there appeared to be a great many of each size class. Because small zooplankton was generally pervasive among the samples (i.e. high percent frequency), we expect them to be more biased in this regard than the other groups. Note, however, that this bias for small zooplankton will tend to reduce cross-correlation between sardine and small zooplankton at small time lags, since the period of sar- dine dominance was generally a period of lower biovolume when small zooplankton dominance would be downgraded by this effect (Ayón et al. 2008b).

\section{Difficulty in ascertaining the relative biovolume for different sized organisms}

Our perception lead observers, when there are many small zooplankters, to upgrade their dominance relative to less common, but much larger, euphausiids or large zooplankton (i.e. the small zooplankton may be much higher in numbers but perhaps lower in biovolume, which leads the observer to upgrade their dominance in the sample). In general, it is difficult to ignore relative numbers in ascertaining dominance by biovolume.

\section{Net mesh size bias}

Another source of bias in the samples, independent of the qualitative aspect of the analysis, is that the net size of the Henson net (300 $\mathrm{mm}$ mesh) excludes from consideration many small zooplankton that pass through the net although they may be important in diets of anchovy and sardine. 